Article

\title{
The Influence of the Degradation of Tetracycline by Free Radicals from Riboflavin-5'-Phosphate Photolysis on Microbial Viability
}

\author{
Shiuh-Tsuen Huang ${ }^{1}$, Shwu-Yuan Lee ${ }^{2}$, Song-Hua Wang ${ }^{3}$, Chun-Yi Wu ${ }^{4}$, Jeu-Ming P. Yuann ${ }^{4}$, \\ Sin $\mathrm{He}^{4}$, Chien-Wei Cheng ${ }^{4, *}$ (i) and Ji-Yuan Liang $4, * \mathbb{B}$ \\ 1 Department of Science Education and Application, National Taichung University of Education, \\ Taichung 40306, Taiwan; hstsuen@mail.ntcu.edu.tw \\ 2 Department of Tourism and Leisure, Hsing-Wu University, New Taipei City 24452, Taiwan; \\ 091007@mail.hwu.edu.tw \\ 3 College of Life and Health Science, Anhui Science and Technology University, Fengyang, \\ Chuzhou 239000, China; shwang70@163.com \\ 4 Department of Biotechnology, Ming-Chuan University, Gui-Shan 33343, Taiwan; \\ kevin1060755@gmail.com (C.-Y.W.); jyuann@mail.mcu.edu.tw (J.-M.P.Y.); peter100d16@gmail.com (S.H.) \\ * Correspondence: ochien@gmail.com (C.-W.C.); liang121@mail.mcu.edu.tw (J.-Y.L.); \\ Tel.: +886-3-350-7001 (ext. 3772) (C.-W.C.); +886-3-350-7001 (ext. 3878) (J.-Y.L.)
}

Received: 12 September 2019; Accepted: 26 October 2019; Published: 28 October 2019

\begin{abstract}
Tetracycline (TC) is a broad-spectrum antibiotic compound. Wastewater with TC may have an adverse effect on ecosystems. Riboflavin-5'-phosphate (FMN or flavin mononucleotide) is a non-toxic product of the phosphorylation of vitamin $\mathrm{B}_{2}$ and is required for the proper functioning of the humans. FMN is sensitized to ultraviolet (UV) and blue light radiation, as evidenced by the generation of reactive oxygen species (ROS). This study inspects feasible applications of blue light on FMN so as to develop a valid way of degrading TC by FMN photolysis. We used the increased rate of bacterial survival as a practical indicator of antibiotic degradation. TC in the presence of FMN solution decomposed completely after $20 \mathrm{~W} / \mathrm{m}^{2}$ of blue light irradiation (TCF treatment), and the degradation of TC (D-TCF) occurred after the photolytic process. After TCF treatment, colony-forming units (CFUs) of Escherichia coli (E. coli) were determined for the D-TCF solution. The CFU of E. coli preservation was $93.2 \%$ of the D-TCF solution $(50 \mu \mathrm{g} / \mathrm{mL}$ of TC in the presence of $114 \mu \mathrm{g} / \mathrm{mL}$ of FMN solution treated with $20 \mathrm{~W} / \mathrm{m}^{2}$ of blue light irradiation at $25^{\circ} \mathrm{C}$ for $1 \mathrm{~h}$ ) cultivation. The mass spectrum of D-TCF showed diagnostic ion signals at $\mathrm{m} / \mathrm{z} 431.0$ and $414.0 \mathrm{Da}$. The molecular formula of D-TCF was $\mathrm{C}_{21} \mathrm{H}_{22} \mathrm{~N}_{2} \mathrm{O}_{8}$, and the exact mass was $430.44 \mathrm{~g} / \mathrm{mol}$. TC degradation by FMN photolysis can significantly decrease the antimicrobial ability of TC. The results expressed here regarding the influence of FMN photolysis on TC degradation offer an environmentally sound wastewater treatment method.
\end{abstract}

Keywords: blue light; tetracycline; free radicals; riboflavin-5'-phosphate; photolysis

\section{Introduction}

The term, "tetracyclines" (TCs), represents a group of broad-spectrum antibiotic compounds. The name tetracycline (TC) comes from its tetracyclic nucleus, which is composed of four linear attached hydrocarbon rings. A variety of functional groups bonded to the nucleus can lead to a tendency toward antibiotic behavior. Therefore, TC is a broad-spectrum antibiotic that can be used against numerous microorganisms, such as Gram-positive and -negative bacteria, protozoan parasites, and so forth. TC interferes with the binding of aminoacyl-transfer ribonucleic acid (aminoacyl-tRNA) 
to the bacterial ribosome and hence suppresses the synthesis of proteins within microorganisms [1]. $\mathrm{TC}$ is widely used in the livestock business for disease prevention, which makes it an important growth promoter of livestock [2]. However, more than $70 \%$ of the TC used by humans is excreted through the urine and feces of humans or animals into the environment, after systemic administration.

The Gram-negative bacterium, E. coli, along with coliforms, was discovered in the digestive systems of animals. E. coli is a pathogen indicator for drinking water and food systems. It is also an indicator of environmental systems. Waste containing TC may present a severe hazard to ecosystems [3]. Therefore, removing TC from waste has become an important issue in relation to maintaining ecosystems.

It is well established that TC is sensitive to ultraviolet (UV) light. Reactive oxygen species (ROS) are generated from TC photolysis under simulated solar irradiation [4]. TC can absorb UV light and be degraded by UV irradiation [5]. Antibiotic photoreaction under solar irradiation is considered a significant approach to degradation in natural aquatic environments [6]. TC is unstable when treated with visible light and is also sensitized to blue light irradiation in an alkaline environment. Anionic superoxide radicals $\left(\mathrm{O}_{2} \bullet^{-}\right)$, in addition to other photolytic products of TC, are generated during the electron-transfer mechanism of TC photolysis [7]. Under blue light irradiation treatment, TC has been used in the photodynamic therapy technique by yield $\mathrm{O}_{2} \bullet^{-}$, which is highly reactive to bacteria inactivation [7].

ROS, for example, the hydroxyl radical $(\bullet \mathrm{OH})$ and superoxide radical $\left(\mathrm{O}_{2} \bullet^{-}\right)$, are normally reactive and small species [8]. Riboflavin (vitamin $\mathrm{B}_{2}, \mathrm{RF}$ ) and riboflavin-5'-phosphate (FMN) are required by humans. They are required by all flavoproteins during energy generation cycles [9]. FMN is produced from the phosphorylation of riboflavin. Both FMN and riboflavin are sensitized to light irradiation [10]. After irradiation under UV [9-13] and blue light [14,15], these two compounds have been shown to attain an excited state via photolysis. The photo-activated riboflavin is transformed into its excited triplet state, and ROS is simultaneously generated $[10,16]$. Riboflavin photolysis was used for the expansion of a secure and valid method for inactivation of pathogens in blood [14,15]. It was reported that HeLa cells treated with FMN or flavin adenine dinucleotide (FAD) under blue light irradiation were subjected to apoptosis through the concomitant ROS production for poisoning tumor cells in vitro [17]. Our previous investigation showed that the inactivation of E. coli and staphylococcus aureus can be achieved by DNA cleavages induced by $\mathrm{O}_{2} \bullet^{-}$production via riboflavin or FMN photolysis $[14,15]$. The riboflavin photolytic reaction has been used to degrade crystal violet $(\mathrm{CV})$, a triphenylmethane dye and an antibacterial agent via ROS generation, leading to a huge decrease in the antimicrobial ability of CV [18].

Heavy metal catalysts, such as titanium dioxide [19,20], strontium titanate [21], zinc oxide [22], ferric oxide [23], and ferrous or ferric iron/hydrogen peroxide [24], as well as UV irradiation have been applied to decompose TC. In addition, the structural changes of TC may alter its molecular property and, accordingly, influence the antibiotic effectiveness of a photochemical process. However, UV radiation and heavy metals are toxic. It has been reported that the antimicrobial ability of TC is decreased by approximately $22 \%$ when TC is treated in the presence of riboflavin solution under Xe or quartz-halogen lamp irradiation for 40 min [25]. Nevertheless, both FMN and riboflavin are sensitized to light irradiation [10]. The water solubility of FMN is enhanced by approximately 200 times, compared with that of riboflavin [10]. However, the levels of ROS production were shown to be higher in FMN than those in riboflavin under blue light irradiation at the same energy dosage [15]. It would be of interest to determine whether adding FMN photolysis can change the structure of TC via ROS generation, which, in turn, would result in a huge decrease in the antimicrobial ability of TC.

In our previous studies, we found that TC is sensitive to blue light irradiation, and the self-photosensitization of TC occurs by the $\mathrm{O}_{2} \bullet^{-}$generated via TC photolysis [7]. TC itself has negligible effects on multidrug-resistant (MDR) E. coli survival. However, following blue light irradiation treatment, the degraded TC significantly inactivates MDR E. coli. The structural modifications of TC can therefore alter its antibiotic property [7]. It has been reported that degraded TC can produce a 
higher stress hazard under UV irradiation via photolytic intermediates [26]. Wastewater containing TC may damage the microbial environments of ecosystems. Thus, microbial viability can be applied as a necessary indicator to evaluate the influences caused by TC pollution.

TC and FMN are both sensitized to blue light, and $\mathrm{O}_{2} \bullet^{-}$is produced via photolytic processes. Further research may compare the ROS generation ability of TC and FMN under blue light irradiation under the same conditions. It would be of interest to investigate the structural changes and the antimicrobial ability of TC via the FMN photolytic process. Thus, if TC degraded by FMN photolysis can largely reduce the antimicrobial ability of TC, a potential and an effective protocol treatment could be obtained.

Treated with blue light irradiation, FMN can degrade TC and eliminate the antimicrobial ability of TC. This study investigated the $\mathrm{O}_{2} \bullet^{-}$generation from TC and FMN irradiated with blue light. Additionally, the effects of FMN photolysis and TC self-photosensitization on TC degradation and structural changes were examined as well. A potential and an effective protocol was developed on the basis of TC degradation via FMN photolysis and treatment with blue light irradiation. The bacterial viability caused by degraded TC provides an index that indicates the impact of the technology.

\section{Materials and Methods}

\subsection{Chemicals}

TC contains a straight fused tetracyclic nucleus. Structures of TC, riboflavin, FMN, lumichrome (LC), and lumiflavin (LF) are shown in Figure 1. L-Methionine, FMN, potassium dihydrogen phosphate, dipotassium phosphate, and TC were acquired from Sigma-Aldrich Co. (St. Louis, MO, USA). Nitro blue tetrazolium chloride (NBT) was purchased from Bio Basic Inc. (Markham, Ontario, Canada). The ultra-pure water, used as the solvent throughout this study, was prepared by a Milli-Q system.

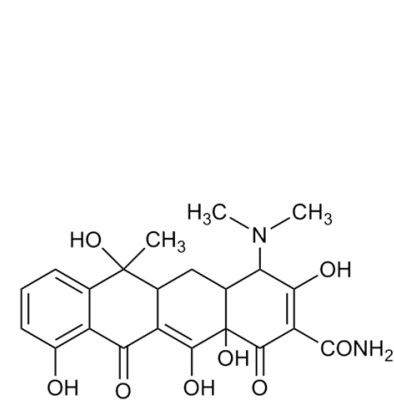

(A) tetracycline (TC)<smiles>Cc1cc2nc3[nH]c(=O)[nH]c(=O)c3nc2cc1C</smiles>

(D) lumichrome (LC)

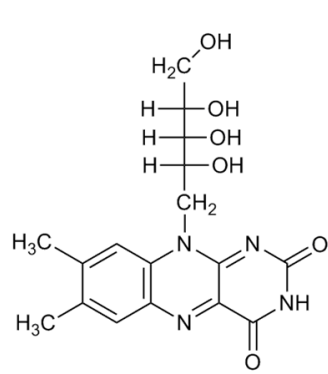

(B) riboflavin (RF)<smiles>Cc1cc2nc3c(=O)[nH]c(=O)nc-3n(C)c2cc1C</smiles>

(E) lumiflavin (LF)

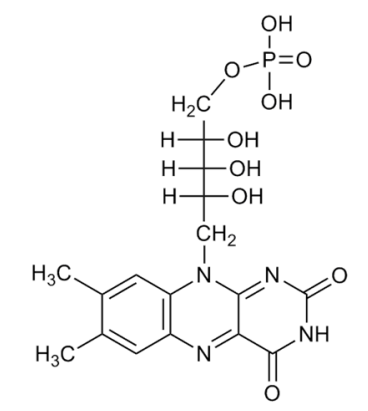

(C) riboflavin-5'-phosphate (FMN)

Figure 1. The chemical structure of (A) tetracycline (TC), (B) riboflavin (RF), (C) riboflavin-5' -phosphate (FMN), (D) lumichrome (LC), and (E) lumiflavin (LF).

\subsection{Set-Up of the Photolysis System}

The photochemical reactions were conducted in a plastic cylinder cup and set in a dark room, as described previously $[7,27,28]$. Six blue light-emitting diode (LED) lights (12V/5050 LED) were purchased from Vita LED Technologies Co. (Tainan, Taiwan). The LED lights were applied as the illuminator by surrounding the inner part of the cup. The emitted maximum wavelength of blue light was $462 \mathrm{~nm}$, and the spectral width at half height $\left(\mathrm{W}_{1 / 2}\right)$ was $23 \mathrm{~nm}$, as measured in a previous study [7]. 
The TM-207 solar power meter made by Tenmars Electronics Co. (Taipei, Taiwan) was employed as an irradiance controller. The experimental setup of the photoreaction system is shown in Figure 2.

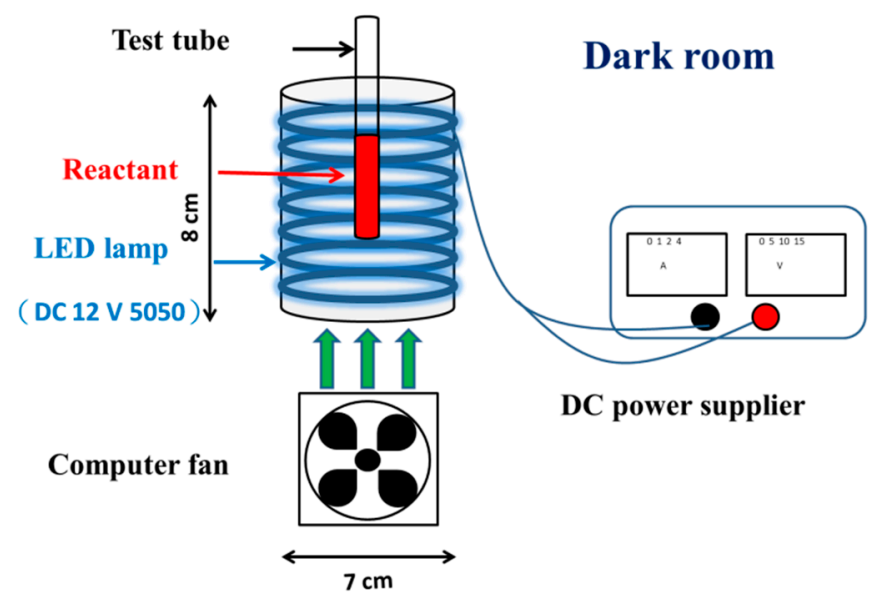

Figure 2. Experimental setup of the photoreaction system. LED: light-emitting diode.

\subsection{FMN or TC under Blue Light Photoreaction}

This study surveyed the blue light effects on FMN and TC degradation. The reaction solution was added to a test tube and positioned on top of the cup. The blue light effects on the photoreactions of FMN and TC were estimated by a UV/VIS spectrometer (Lambda 35, Perkin-Elmer, Waltham, MA, USA). The reaction solution was either $50 \mu \mathrm{g} / \mathrm{mL}$ of TC or $50 \mu \mathrm{g} / \mathrm{mL}$ of FMN in $0.1 \mathrm{M}$ phosphate buffer solution (PBS, pH 7.8). Briefly, (i) reaction solutions of TC and FMN in the dark separately were treated as a control group, (ii) the reaction solution of either TC or FMN was maintained under blue light irradiation at $20 \mathrm{~W} / \mathrm{m}^{2}$ for $0-30 \mathrm{~min}$, and (iii) a different batch of the reaction solution of $50 \mu \mathrm{g} / \mathrm{mL}$ of TC mixed with $50 \mu \mathrm{g} / \mathrm{mL}$ of FMN in PBS was maintained under blue light irradiation at $20 \mathrm{~W} / \mathrm{m}^{2}$ for 0-30 min at $10 \pm 1{ }^{\circ} \mathrm{C}$ in a cold room. The absorbance of the reaction solutions was surveyed at $300-800 \mathrm{~nm}$ via UV/VIS.

\subsection{Detection of $\mathrm{O}_{2} \bullet^{-}$}

$\mathrm{O}_{2} \bullet^{-}$can be detected by direct or indirect methods. The direct method uses a more delicate instrument, for example, electron paramagnetic resonance (EPR) spectroscopy. The indirect methods are better for examination [28]. Indirect methods, such as the reduction of nitro blue tetrazolium (NBT), have been applied to measure the $\mathrm{O}_{2} \bullet^{-}$activity in riboflavin or FMN photoreactions [27,29]. NBT is reduced by the $\mathrm{O}_{2} \bullet^{-}$generated from intermediates [30] and is an indirect assay used to inspect $\mathrm{O}_{2} \bullet^{-}$. Under blue light irradiation, this study investigated the impact of the molecular alterations of TC and FMN on $\mathrm{O}_{2} \bullet^{-}$production.

The reaction solutions were made fresh, prior to the experiments. Initially, $109.3 \mathrm{mg}$ of L-methionine was mixed with $75 \mathrm{~mL}$ of PBS. Afterward, $25 \mathrm{~mL}$ of $200 \mu \mathrm{g} / \mathrm{mL}$ TC (or $200 \mu \mathrm{g} / \mathrm{mL}$ FMN) and $10 \mathrm{mg}$ of NBT were added to the mixed solution, that is, the final concentrations of TC (or FMN), L-methionine, and NBT were 50 (50), 1090, and $100 \mathrm{mg} / \mathrm{L}$, respectively. The reaction solutions were irradiated at $20 \mathrm{~W} / \mathrm{m}^{2}$ by blue light for different time intervals at room temperature. The $\mathrm{O}_{2} \bullet^{-}$produced from the photolytic reactions reduced NBT to yield formazan detected at $560 \mathrm{~nm}$.

\subsection{Influences of TC and Degraded TC on Bacterial Viability}

In our previous study, $50 \mu \mathrm{g} / \mathrm{mL}$ of TC had insignificant efficacy on MDR E. coli survival at 10 and $25^{\circ} \mathrm{C}$ [7]. The changed conformation of TC after blue light irradiation and self-photosensitization can therefore alter its antibiotic property, and the change configuration of TC maintained the antibacterial ability of MDR E. coli through photolysis [7]. In our previous study, blue light-induced photolysis 
with riboflavin or FMN was found to generate ROS to inactivate E. coli and lead to the degradation of crystal violet (CV) [18]. The cultivation of bacteria and the TC (FMN) photochemical reaction may increase, along with the reaction temperature, at 10 and $25^{\circ} \mathrm{C}$. The structural changes of TC under the FMN photolytic process and the changed structure of TC retain or reduce the antimicrobial ability at different temperatures and are therefore interesting to investigate.

The involvement of both TC and degraded TC in the antibacterial ability of E. coli were examined in this study. The irradiation conditions were the same as those described in Section 2.3. In brief, (i) PBS was left in the dark and served as a control, (ii) 20 or $50 \mu \mathrm{g} / \mathrm{mL}$ of TC in PBS was left in the dark, and (iii) 20 or $50 \mu \mathrm{g} / \mathrm{mL}$ of TC with $114 \mu \mathrm{g} / \mathrm{mL}$ of FMN in PBS was maintained under blue light irradiation at $20 \mathrm{~W} / \mathrm{m}^{2}$ for $2 \mathrm{~h}$ (TCF treatment; energy dose, $14.4 \mathrm{~J} / \mathrm{cm}^{2} ; 1 \mathrm{~W} \times \mathrm{h}=3600 \mathrm{~J}, 20 \mathrm{~W} / \mathrm{m}^{2} \times 2 \mathrm{~h}$ $\left.=144,000 \mathrm{~J} / \mathrm{m}^{2}=14.4 \mathrm{~J} / \mathrm{cm}^{2}\right)$. Meanwhile, the reaction settings were maintained at $10 \pm 1{ }^{\circ} \mathrm{C}$. As for the TCF treatment, experiments were performed at room temperature, that is, $25 \pm 3{ }^{\circ} \mathrm{C}$ for 0.5 (energy dose, $3.6 \mathrm{~J} / \mathrm{cm}^{2}$ ) or $1 \mathrm{~h}$ (energy dose, $7.2 \mathrm{~J} / \mathrm{cm}^{2}$ ) to inspect how temperature influences E. coli inactivation.

The DH5 $\alpha$ strain of E. coli (NCBI 668369) was developed for laboratory cloning use and cultivated in Luria Bertoni (LB) media at $37^{\circ} \mathrm{C}$ overnight. After harvest, $500 \mu \mathrm{L}$ of bacterial broth loaded put in a $1.5 \mathrm{~mL}$ centrifuge tube and diluted with water. Then, cultures were cultivated to reach an optical density of 0.5 at $600 \mathrm{~nm}\left(\mathrm{OD}_{600}\right)$, for which the bacterial density was about $4.1 \times 10^{7} \mathrm{CFU} / \mathrm{mL}$. The supernatant was removed after centrifugation for $5 \mathrm{~min}$. Prior to resuspension, $1 \mathrm{~mL}$ of TC or degraded TC from the TCF treatment (D-TCF) was added to the pellet, whereas the PBS without TC was used as a control. The bacterial solution in the presence of TC or D-TCF was then incubated for $1 \mathrm{~h}$. Then, $200 \mu \mathrm{L}$ of bacterial solution was placed on Luria agar plates and cultured at $37^{\circ} \mathrm{C}$ overnight. The E. coli survival rate after each treatment was inspected by the viable plate count. The inactivation rate of $E$. coli was calculated according to the reducing percentage of the viable cells, $(1-\mathrm{C} / \mathrm{N}) \times 100 \%$, where $\mathrm{C}$ and $\mathrm{N}$ are the numbers of CFUs for each test of either TC or degraded TC treatment (C) and no TC treatment $(\mathrm{N})$, respectively. Then, the reduction rate of CFUs was expressed as the negative numerical value of the inactivation rate.

\subsection{TC and D-TCF Analysis by LC-MS/MS}

The FMN photolytic reaction on TC degradation was analyzed using an LC-MS/MS method. The separation of TC and FMN in the solutions is described in Section 2.3. The samples were maintained under blue light irradiation at $20 \mathrm{~W} / \mathrm{m}^{2}$ for $1 \mathrm{~h}$. TC, FMN, and D-TCF were eluted by an Agilent Poroshell 120 EC-C18 column $(2.7 \mu \mathrm{m}, 4.6 \mathrm{~mm} \times 150 \mathrm{~mm}$, Agilent Technologies, Palo Alto, CA, USA), followed by LC-MS/MS analysis. Using an Agilent 1200 Series HPLC System, an electrospray ionization (ESI) source was connected to an Agilent 6410B triple quadrupole MS in this study.

The mobile phase was composed of $0.1 \%$ methanoic acid (A) and methanol (B). The process of separation was completed by a mobile phase, the profile of which is depicted below. The linear gradient started with $0-2 \mathrm{~min}, 95 \%-80 \%$ A; $2-8 \mathrm{~min}, 80 \% \mathrm{~A} ; 8-12 \mathrm{~min}, 80 \%-40 \% \mathrm{~A} ; 12-15 \mathrm{~min}, 40 \% \mathrm{~A}$; $15-19 \mathrm{~min}, 40 \%-5 \% \mathrm{~A} ; 19-24 \mathrm{~min}, 5 \% \mathrm{~A}$; and $24-27 \mathrm{~min}, 5 \%-95 \% \mathrm{~A}$. The final mobile phase was set at $95 \%$ solvent A from 27 to $30 \mathrm{~min}$. The reaction solution at a volume of $10 \mu \mathrm{L}$ was injected at a flow rate of $0.4 \mathrm{~mL}$ per minute. TC or D-TCF was investigated by a positive-ion mode for charged fragments. The data were obtained and inspected using the MassHunter Workstation software, version B.06.00.

\subsection{Statistics}

The results were expressed as the mean \pm standard deviation (SD) of at least three individual tests. A homoscedastic two-tailed Student's $t$-test was used for the determination of differential significance between two measurements. The difference between two groups was considered statistically significant $(p<0.05)$. 


\section{Results}

\subsection{Spectral Effects of Blue Light on FMN and TC}

The spectra of the FMN and TC solutions treated with blue LED lamp for 0-30 min are shown in Figure 3. In the FMN solution, two maxima at 373 and $445 \mathrm{~nm}$ were observed in the absorption spectrum of the FMN dark control, and the peak at $445 \mathrm{~nm}$ was significantly reduced after $10 \mathrm{~min}$ of blue light irradiation, as shown in Figure 3A. In the TC solution, one peak at $364 \mathrm{~nm}$ was detected for the dark control, and the absorption at $364 \mathrm{~nm}$ was extensively decreased after blue light irradiation for $30 \mathrm{~min}$. The spectra of the TC in the FMN solution under blue light irradiation for 0-30 min are shown in Figure 3C. For TC, in the presence of the FMN solution, two peaks of the mixed solution, 368 and $445 \mathrm{~nm}$, were observed in the spectrum of the dark control, and the spectrum of the mixed solution with a maximal absorbance at $348 \mathrm{~nm}$ was inspected after $30 \mathrm{~min}$ of blue light irradiation. In our previous study, blue light-induced photolysis with FMN was found to generate ROS, and the spectrum absorbance of FMN was reduced drastically at $445 \mathrm{~nm}$ after blue light irradiation, which may have been due to the isoalloxazine ring photoreduction by electron migration from the ribityl side-chain of FMN [15]. TC was also unstable when irradiated by blue light, as seen in Figure 3B. In our previous study, the $\mathrm{O}_{2} \bullet^{-}$was yielded from TC treated under blue light, and the molecular formula of the photolysis product was $\mathrm{C}_{22} \mathrm{H}_{22} \mathrm{~N}_{2} \mathrm{O}_{9}$ [7]. As seen in Figure 3B,C, the spectrum absorbance of the TC treated without and with FMN was shifted from 368 to $348 \mathrm{~nm}$ after blue light irradiation for $30 \mathrm{~min}$. It was uncertain whether the change of the photolytic product of TC occurred through the TC treated with or without FMN after 30 min of blue light irradiation in this section.
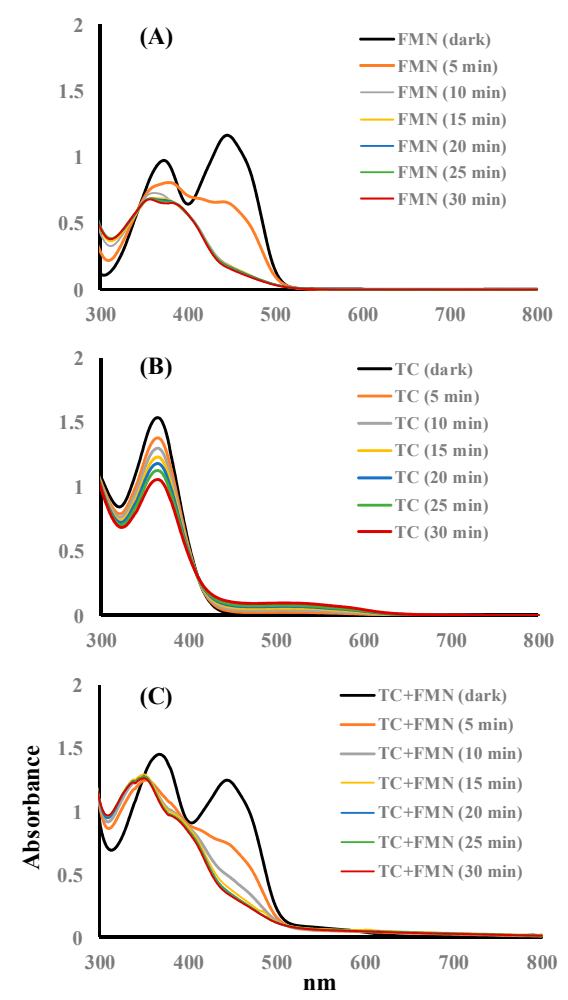

Figure 3. Absorption spectra after 0-30 min of blue light irradiation at $20 \mathrm{~W} / \mathrm{m}^{2}$ of (A) $50 \mu \mathrm{g} / \mathrm{mL}$ of FMN, (B) $50 \mu \mathrm{g} / \mathrm{mL}$ of TC, and (C) $50 \mu \mathrm{g} / \mathrm{mL}$ of FMN in the presence of $50 \mu \mathrm{g} / \mathrm{mL}$ of TC. The absorbances of the reaction solutions were collected in the wavelength from 300 to $800 \mathrm{~nm}$.

\subsection{Detection of $\mathrm{O}_{2} \bullet-$ via FMN or TC Photolysis}

The generation of $\mathrm{O}_{2} \bullet-$ from FMN and TC via blue light irradiation was studied by the NBT reduction method $[7,15,27]$. The reduction profiles in the FMN/NBT and TC/NBT systems under blue 
light irradiation for different time intervals are shown in Figure 4. In Figure 4, whether the blue light photoreduction of NBT in FMN or TC solution, an increasing time-dependent pattern was detected. It suggests that FMN or TC photolysis generates $\mathrm{O}_{2} \bullet^{-}$, which is involved in the photochemical system. The slopes of the NBT reaction curve of the ROS production for TC and FMN at the same conditions were 0.0015 and 24.488, respectively, as shown in Figure 4.
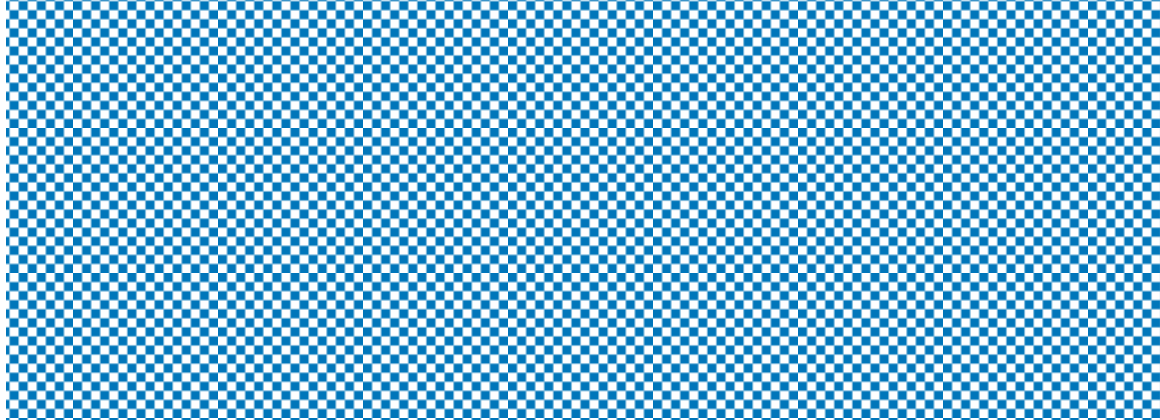

Figure 4. Effects of (A) TC and (B) FMN on nitro blue tetrazolium (NBT) reduction under blue light irradiation at $20 \mathrm{~W} / \mathrm{m}^{2}$. The symbols $(\bullet)$ in blue are the averaged absorbance of experimental data at different time points.

\subsection{Effects of TC and D-TCF on E. coli Viability}

In this study, the microbial viability due to D-TCF (TC in $114 \mu \mathrm{g} / \mathrm{mL}$ of FMN solution at $\mathrm{pH}$ 7.8 , treated under blue light at $20 \mathrm{~W} / \mathrm{m}^{2}$, TCF treatment) was also explored. As shown in Figure 5, it seems that, for E. coli, the higher the concentration of the TC treatment, the higher the reduction percentage. The inactivation rates of $26.7 \%$ and $69.1 \%$ on $E$. coli were achieved via the 20 and $50 \mu \mathrm{g} / \mathrm{mL}$ TC treatments at $10 \pm 1{ }^{\circ} \mathrm{C}$, respectively, as shown in Figure 5. Under TCF treatment at $10 \pm 1{ }^{\circ} \mathrm{C}$ for $2 \mathrm{~h}$, the inactivation rates of $0.49 \%$ and $5.79 \%$ were achieved on E. coli via 20 and $50 \mu \mathrm{g} / \mathrm{mL}$ of D-TCF solution, respectively, but the inactivation rates of the two treatments were not significantly different $(p>0.05)$, as shown in Figure 5, implying that 20 and $50 \mu \mathrm{g} / \mathrm{mL}$ of TC treated with FMN solution, after blue light irradiation treatment at $10 \pm 1{ }^{\circ} \mathrm{C}$, undergo conformational changes. In our previous study, conformationally changed TC at $50 \mu \mathrm{g} / \mathrm{mL}$ enhanced the antibiotic ability of MDR E. coli upon blue light irradiation [7]. Comparing the changes of structure under the same condition, $50 \mu \mathrm{g} / \mathrm{mL}$ of TC treated with FMN solution after blue light irradiation at $25^{\circ} \mathrm{C}$ was chosen in this study.

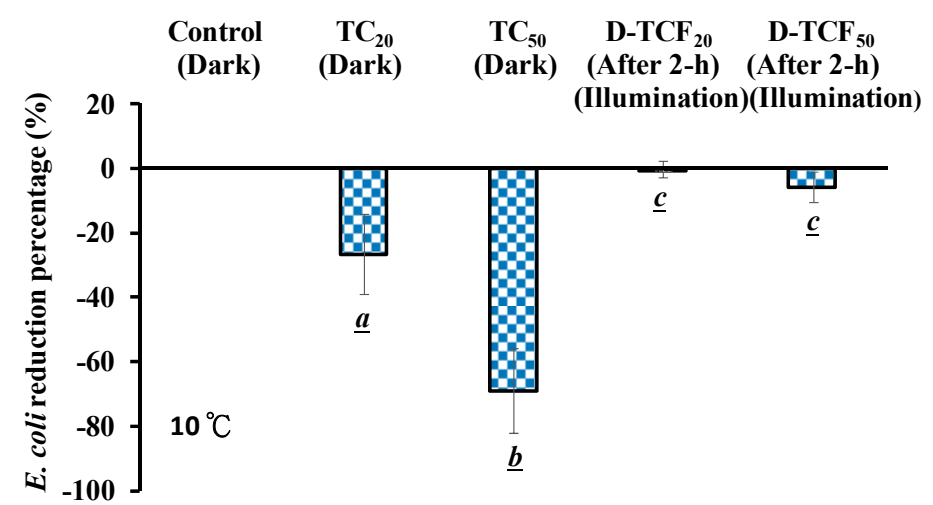

Figure 5. Effects of TC and degradation of TC (D-TCF) on E. coli viability at $10 \pm 1{ }^{\circ} \mathrm{C}$. Data are expressed as the mean $\pm \mathrm{SD}$, where $n=3$. Statistically significant difference $(p<0.05)$ between an experimental group and the control is indicated by a letter below the each bar. Any two experimental groups that are significantly different between each other are labeled by different letters. 
The effects of D-TCF on the viability of E. coli at $25 \pm 3{ }^{\circ} \mathrm{C}$ were also investigated. In Figure 6, the reduction percentage of $E$. coli was found to increase significantly with the TC treatment at room temperature. Under the TCF treatment at $25 \pm 3{ }^{\circ} \mathrm{C}$ for 0.5 and $1 \mathrm{~h}$, the inactivation rates of $35.2 \%$ and $6.8 \%$ on E. coli were achieved via $50 \mu \mathrm{g} / \mathrm{mL}$ of D-TCF solution, respectively, as shown in Figure 6.

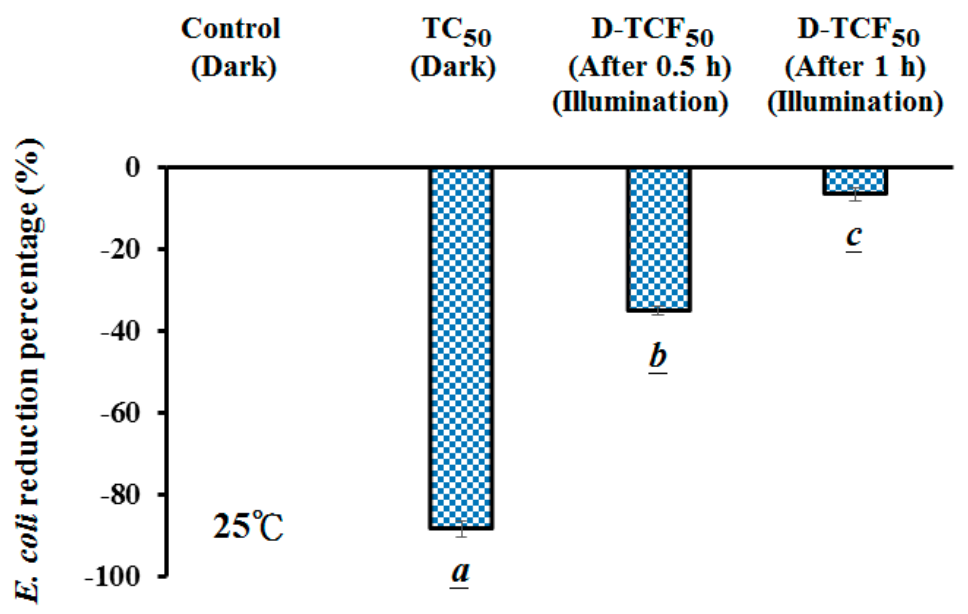

Figure 6. Effects of TC and D-TCF on E. coli viability at $25 \pm 3{ }^{\circ} \mathrm{C}$. Data are expressed as the mean $\pm \mathrm{SD}$, where $n=3$. Statistically significant difference $(p<0.05)$ between an experimental group and the control is indicated by a letter below the bar. Any two experimental groups that are significantly different between each other are labeled by different letters.

\subsection{Molecular Identification via LC-MS/MS Analyses}

The solutions of FMN and TC after blue light treatment were analyzed via LC-MS/MS. In Figure 7A, the total ion chromatogram of the PBS at pH 7.8 can be observed at $3.4 \mathrm{~min}$. FMN is a derivative of riboflavin, obtained by the phosphorylation of the ribityl side-chain. In Figure 7A, the total ion chromatograms of FMN at pH 7.8, without photolysis processing, were observed at $16.63 \mathrm{~min}$ (FMN) and $17.376 \mathrm{~min}$ (Pro-RF). In Figure 7, the peak labeled as Pro-RF eluted at $17.376 \mathrm{~min}$ was identified as riboflavin by the major ion fragment at $\mathrm{m} / \mathrm{z}$ 377.1, which is described in the Results section. As shown in Figure 7B, the TC at $\mathrm{pH} 7.8$, without photolysis processing, was observed at $16.734 \mathrm{~min}$. In Figure 7C, for the TC treated with FMN, the total ion chromatogram containing compounds eluted at 16.734 (D-TCF), 18.271 (LF), and $20.614 \mathrm{~min}$ (LC) after $20 \mathrm{~W} / \mathrm{m}^{2}$ of blue light irradiation at $25 \pm 3^{\circ} \mathrm{C}$ for $1 \mathrm{~h}$, as shown below.

In Figure 8, the electron ionization mass spectra, after the analyses of FMN and TC photolysis, are presented. The FMN is observed at $16.63 \mathrm{~min}$, as shown in Figure 7A. The major ion fragment of FMN was at $\mathrm{m} / \mathrm{z}$ 457.1, as shown in Figure 8A. The Pro-RF is observed at $17.376 \mathrm{~min}$, as shown in Figure 7A. The compound of Pro-RF was confirmed by the major ion fragment at $\mathrm{m} / \mathrm{z} 377.1$, as shown in Figure $8 \mathrm{~B}$, and it thus could be identified as riboflavin. In Figure 7B, TC is observed at $16.734 \mathrm{~min}$ with the major ion fragment of $\mathrm{m} / \mathrm{z} 445.1$, as shown in Figure 8C. The D-TCF was noticed at $16.734 \mathrm{~min}$ via the TC treated with FMN photolysis, as shown in Figure 7C. The major ion fragment of the mass spectrum of D-TCF was at $\mathrm{m} / \mathrm{z}$ 431.0, as shown in Figure 8D. The emerging peaks, LF and LC, were noticed at 18.271 and $20.614 \mathrm{~min}$, respectively. Furthermore, the compounds of LF and LC were verified by their mass spectra, showing major ions of m/z 257.0 and 243.0, as seen in Figure 8E,F, respectively, and thus identified as lumiflavin and lumichrome. 


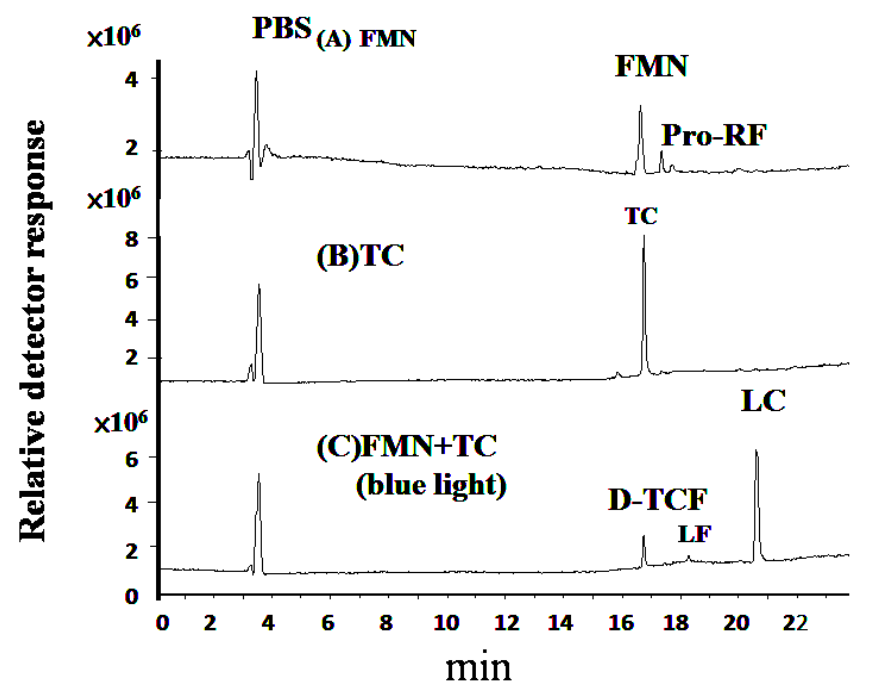

Figure 7. The chromatograms of the HPLC-MS analyses of (A) FMN (pH 7.8), (B) $50 \mu \mathrm{g} / \mathrm{mL}$ of TC solution, and (C) $50 \mu \mathrm{g} / \mathrm{mL}$ of TC in FMN solution after $20 \mathrm{~W} / \mathrm{m}^{2}$ blue light irradiation at $25 \pm 3{ }^{\circ} \mathrm{C}$ for 1 h. PBS: phosphate buffer solution. Notice that the Pro-RF in (A) coeluted with FMN is confirmed as riboflavin and described in the Results section.

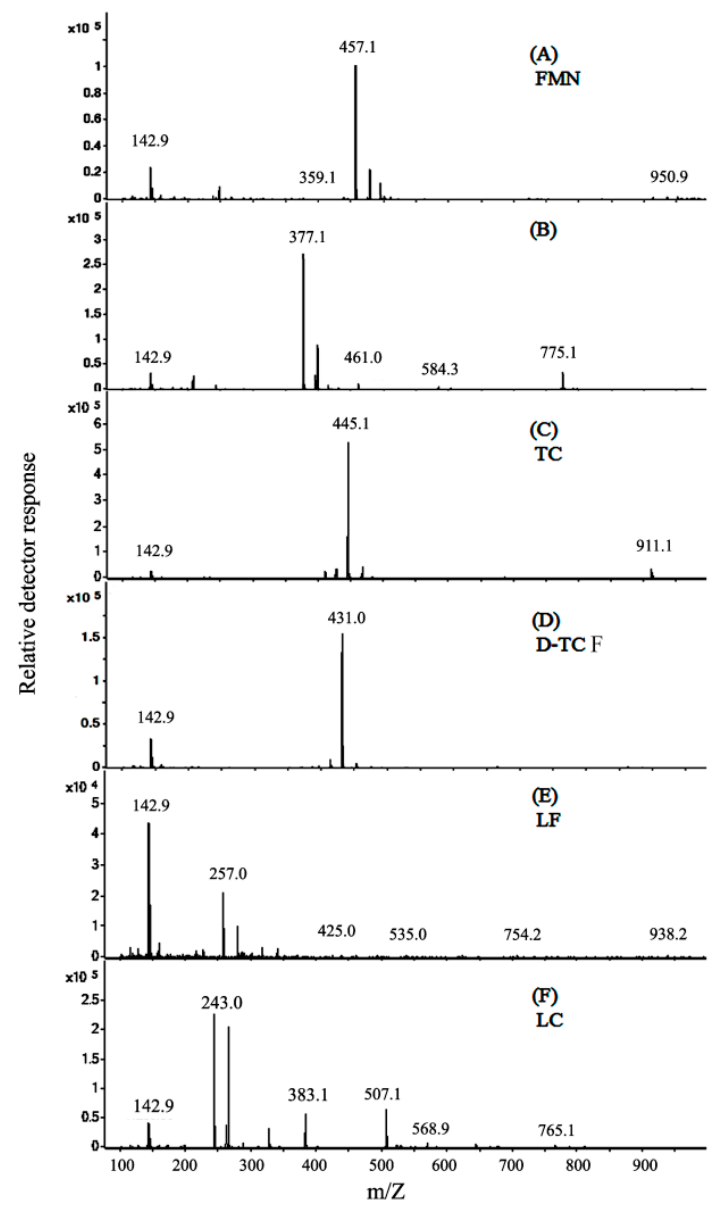

Figure 8. Spectra of (A) FMN, (B) riboflavin, (C) TC, (D) D-TCF, (E) lumiflavin, and (F) lumichrome from the TC treated with FMN under blue light irradiation for $1 \mathrm{~h}$. The ionic spectral product of $[\mathrm{M}+\mathrm{H}]^{+}$is considered to be blue light-altered TC in solution ( $\mathrm{pH} 7.8$ ). The precursor ion of $\mathrm{m} / \mathrm{z} 445$ was selected, and the proposed fragments are shown in each spectrum. 


\section{Discussion}

FMN, a non-toxic micronutrient and a photosensitive compound, is essential for human bodily functions. A photosensitizer can be applied as an ingredient to catalyze the degradation of chemicals to produce reactive species, such as ROS, by irradiation. The current study showed that the antibacterial ability of TC can be decreased by blue light-induced ROS using FMN. The photolytic procedure of FMN can thus greatly reduce the antimicrobial capability of TC. Therefore, this method has the potential to be an environmentally sound method for wastewater treatment.

The molecular formula of TC is $\mathrm{C}_{22} \mathrm{H}_{24} \mathrm{~N}_{2} \mathrm{O}_{8}$ (MW, $444.44 \mathrm{~g} / \mathrm{mol}$ ), and it is sensitive to blue light. For the TC in solution, the absorption of TC at $364 \mathrm{~nm}$ was considerably decreased, and $\mathrm{O}_{2} \bullet^{-}$was generated via blue light irradiation, on the basis of this study. The effects caused by TC after blue light irradiation treatment at $20 \mathrm{~W} / \mathrm{m}^{2}$ for $2 \mathrm{~h}$ (TC-B) on the survival rate of E. coli were significantly increased in our previous study [7]. Conformational changes of TC may influence its antibiotic effectiveness in the solution as well. Both TC and FMN are sensitive to blue light, so the photolytic productions of TC alone and TCF treatments were compared. The photolysis of TC alone under blue light irradiation did not cause much degradation of TC, with the main compounds being TC (MW, $444.44 \mathrm{~g} / \mathrm{mol}$ ) and the photochemical product of TC-B (MW, $458.44 \mathrm{~g} / \mathrm{mol}$ ), as shown in a previous study [7]. TC, in the presence of FMN, decomposed completely in the solution after blue light irradiation treatment, and the exact mass of the product (D-TCF) was $430.44 \mathrm{~g} / \mathrm{mol}$ in this study.

As shown in Figure 3B, the absorption at $364 \mathrm{~nm}$ was extensively decreased after $30 \mathrm{~min}$ of blue light irradiation, and the TC expression rate is assumed to follow a model that undergoes a pseudo-first-order kinetics (Equation (1)), as studied previously [7]. Equation (2) can be acquired, from $t=0$ to $t=\mathrm{t}$, by integrating Equation (1). Thus, the TC photolysis kinetics in PBS was imitated, according to a model of pseudo-first-order kinetics, shown below.

$$
\begin{gathered}
-\frac{d C_{T C}}{d t}=k_{\text {appa. }} \times C_{T C}, \\
-\ln \frac{C_{T C}}{C_{0}}=k_{\text {appa. }} \times t .
\end{gathered}
$$

where $C_{0}$ and $C_{T C}$ are the primary concentrations of TC and the concentration of TC at the reaction time, respectively. The term $k_{\text {appa. }}$ is the rate constant of apparent decomposition. The peak at $445 \mathrm{~nm}$ was significantly reduced after $10 \mathrm{~min}$ of irradiation by blue light in the FMN solution, as shown in Figure 3A. $k_{\text {appa. }}$ from $50 \mu \mathrm{g} / \mathrm{mL}$ of TC or $50 \mu \mathrm{g} / \mathrm{mL}$ of FMN were used to compare the photolytic ability via blue light irradiation at $20 \mathrm{~W} / \mathrm{m}^{2}$, as shown in Figure 9 . As Figure 9 shows, the $k_{\text {appa. }}$ of TC or FMN, under blue light irradiation at $20 \mathrm{~W} / \mathrm{m}^{2}$, were 0.0104 or $0.1046\left(\mathrm{~min}^{-1}\right)$, respectively. In addition, the kinetics of photolysis indicated that the photolysis efficiency of FMN was faster under blue light than that of TC. The formation of $\mathrm{O}_{2} \bullet^{-}$was analyzed using the FMN/NBT and TC/NBT systems, as shown in Figure 4. The slope of the NBT reduction method of FMN was much steeper than that of TC in this study. That is, the level of ROS generation in FMN photolysis under blue light irradiation was much higher than what occurs in TC, and the better property of FMN photolysis, in terms of generating radical species, may be ascribed to its photosensitivity to blue light or perhaps any other photoradiation with sufficient frequency.

According to the consequences of the current study, a scheme for the mechanism of FMN/TC photodegradation was proposed, as shown in Figure 10. The processes of the initial photochemical reactions of flavins are represented in Equation (3).

$$
\text { flavins }+\mathrm{h} v \rightarrow{ }^{1} \text { flavins } \rightarrow{ }^{3} \text { flavins }{ }^{*}
$$

where ${ }^{1}$ flavins ${ }^{*}$ and ${ }^{3}$ flavins ${ }^{*}$ are the excited singlet and triplet states of the flavins, respectively. The degradation mechanisms of these photoinduced flavins were likely initiated by a triplet-triplet annihilation or a triplet-ground state quenching process [25,31-33], the latter of which is depicted 
in this study. The TC directly oxidized by an electron abstraction through an electron transfer event from the TC ground state was started via flovin-sensitised irradiation [25]. TC and the ground state of flavins (flavins $s_{0}$ ) are the electron donors, which can offer an electron to ${ }^{3}$ flavins ${ }^{*}$ and generate the semi-reduced (flavins $\bullet^{-}$) and semi-oxidized $\left(\mathrm{TC} \bullet^{+}\right.$, flavins $\bullet^{+}$) forms, respectively, as shown in Equations (4) and (5).

$$
\begin{aligned}
{ }^{3} \text { flavins }^{*}+\mathrm{TC} & \rightarrow \text { flavins }^{\bullet-}+\mathrm{TC}^{\bullet+}, \\
{ }^{3} \text { flavins }^{*}+\text { flavins }_{0} & \rightarrow \text { flavins }^{\bullet-}+\text { flavins }^{\bullet+-} .
\end{aligned}
$$

The photodegradation pathways of TC and flavins are achieved by flavin photosensitization. The TC and flavins were promoted to the electronically excited state, TC $\bullet$ and flavins $\bullet$, via a photolytic process, and the flavins were reduced by losing an electron, as shown in Equations (6)-(14).

$$
\begin{aligned}
& \mathrm{TC}+\mathrm{h} v \rightarrow \mathrm{TC}^{\bullet}, \\
& \mathrm{TC}^{\bullet}+\text { flavins } \rightarrow \mathrm{TC}^{\bullet+}+\text { flavins }\left(\mathrm{e}^{-}\right) \rightarrow \mathrm{TC}^{\bullet+}+\text { flavins }{ }^{\bullet}, \\
& \mathrm{TC}^{\bullet+} \stackrel{-\mathrm{H}^{+}, \mathrm{O}^{2}, \underset{\rightarrow}{\rightarrow}}{\rightarrow} \mathrm{O}_{2^{\bullet-}, \mathrm{H}_{2} \mathrm{O}} \text { degraded compounds, } \\
& \text { flavins }+\mathrm{h} v \rightarrow \text { flavins }{ }^{\bullet} \text {, } \\
& \text { flavins } \bullet^{\bullet}+\text { flavins } \rightarrow \text { flavins }^{\bullet+}+\text { flavins }\left(\mathrm{e}^{-}\right) \rightarrow \text { flavins }^{\bullet+}+\text { flavins }{ }^{\bullet-} \text {, } \\
& \text { flavins } \bullet \stackrel{-H^{+}}{\rightarrow} \text { flavins }(-\mathrm{H}) \stackrel{-e^{-}}{\rightarrow} \text { degraded compounds, }
\end{aligned}
$$

where $\mathrm{TC}^{+}{ }^{+}$and flavins ${ }^{\bullet+}$ are both radical and cation species.

Simultaneously, the interaction of flavins ${ }^{\bullet-}$ with $\mathrm{O}_{2}\left({ }^{3} \Sigma \mathrm{g}^{-}\right)$can generate the reactive superoxide ion, $\mathrm{O}_{2} \bullet^{-}$, followed by the hydroperoxyl radical, $\mathrm{HOO} \bullet$, which is generated by a reaction between $\mathrm{O}_{2} \bullet^{-}$and a hydrogen atom and causes the degradation of flavins ${ }_{0}$.

$$
\begin{gathered}
\text { flavins }^{\bullet-}+\mathrm{O}_{2}\left({ }^{3} \Sigma_{\mathrm{g}^{-}}\right) \rightarrow \text { flavins }_{0}+\mathrm{O}^{2 \bullet-}, \\
\mathrm{O}^{2 \bullet-}+\mathrm{H}^{+} \rightarrow \mathrm{HOO}^{\bullet}, \\
\mathrm{HOO}^{\bullet}+\text { flavins }_{0} \rightarrow \mathrm{H}_{2} \mathrm{O}_{2}+\text { flavins }(-\mathrm{H})^{\bullet} \stackrel{-e^{-}}{\rightarrow} \text { degraded compounds. }
\end{gathered}
$$

where flavins ${ }^{\bullet-}$ is a radical anion.

As depicted in Figure 10, flavins treated with blue light irradiation can reach an electronically excited state (flavins*), whereas the abstraction in the selective $\mathrm{C}-\mathrm{H}$ bond of the $\mathrm{N}$-methyl group in TC can form an aminium radical cation via an initial single electron transfer, as shown in Figure 10D [34]. A further deprotonation $\left(-\mathrm{H}^{+}\right)$of $\alpha-\mathrm{C}$ leads to the formation of a carbon-centered radical. The carbon-centered radical reacts rapidly with dissolved oxygen to generate a peroxyl radical, perhaps followed by the loss of a superoxide radical $\left(\mathrm{O}_{2} \bullet^{-}\right)$to yield an iminium cation. It is well known that imine, due to its chemical instability in aqueous solution, undergoes fast hydrolysis, as the aforementioned $N$-demethylation product, D-TCF (m/z 431), is formed, as shown in Figure 10M. In short, a single electron transfer and hydrogen abstraction from the TC, exciting flavins under photolytic treatment, are able to follow a process with an iminium intermediate, which later underwent hydration and oxidation to become additional intermediates, as shown in Figure 10J-L, and generated the demethylated product [35].

Huvaere et al. (2010) [36] reported that the electron transfer from flavins ${ }_{0}$ to the oxidizing ${ }^{3}$ flavins* $^{*}$ can generate a reduced flavin radical (flavins ${ }^{\bullet-}$ ), which can be readily oxidized by residual oxygen to regenerate the incipient flavins $s_{0}$ and the concomitant formation of superoxide $\left(\mathrm{O}_{2} \bullet^{-}\right)$, as shown in Figure 10E. The highly reactive flavin radical cation (flavins ${ }^{\bullet+}$ ) was generated simultaneously under the photolytical process with a self-quenching (oxidized flavin) reaction, as shown in Figure 10F. 

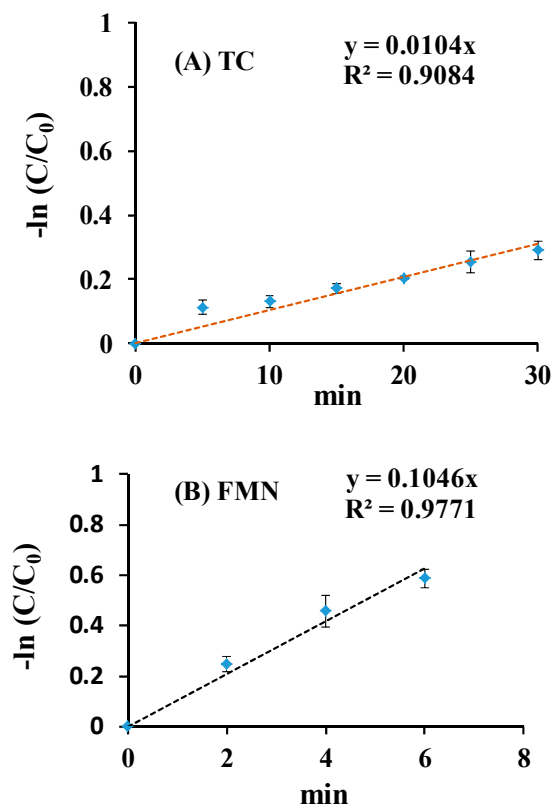

Figure 9. The $\mathrm{k}_{\mathrm{appa}}$ of (A) TC and (B) FMN treated with blue light irradiation at $20 \mathrm{~W} / \mathrm{m}^{2}$.

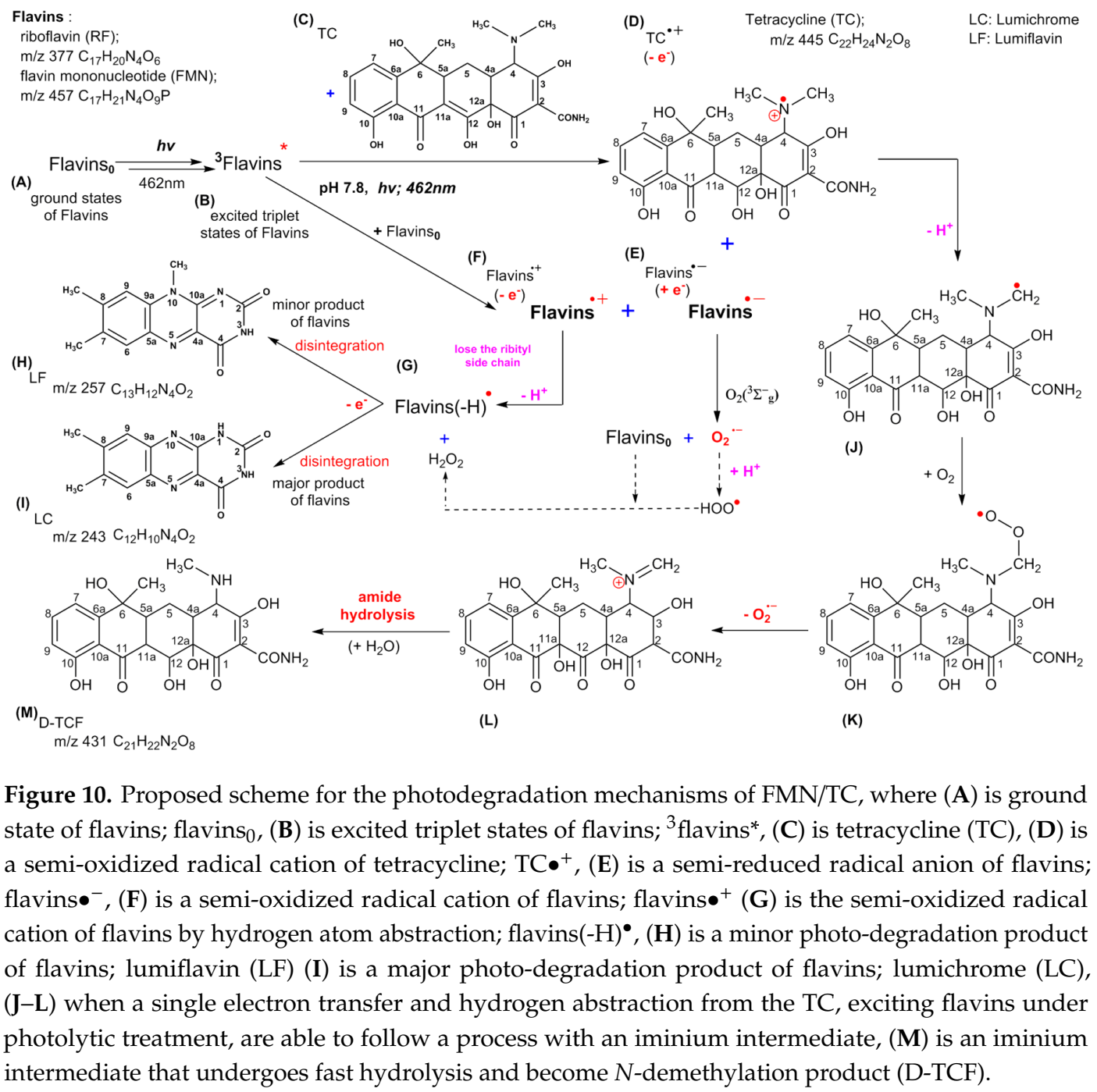


The flavins $\boldsymbol{\bullet}^{-}$were readily oxidized to generate the incipient flavins ${ }_{0}$ and $\mathrm{O}_{2} \bullet^{-}$. The reactive hydroperoxyl radical $\left(\mathrm{HOO} \bullet\right.$ ) could be formed via the process in which a proton is added to $\mathrm{O}_{2} \bullet^{-}$, leading to the degradation of flavins, as shown in Figure 10G. The flavins $(-\mathrm{H})^{\bullet}$ could also be produced via hydrogen atom abstraction from the flavins ${ }^{\bullet+}$. In that case, the flavins $(-\mathrm{H})^{\bullet}$ would release an electron, which would cause the degradation of flavins, as shown in Figure 10G [32]. In photodegradation of flavins, the flavin solution disintegrates into a series of products via the light-induced autoreaction with the most characteristic molecular ions $\left([\mathrm{M}+\mathrm{H}]^{+}\right)$thus formed, that is, $\mathrm{m} / \mathrm{z} 257$ and $\mathrm{m} / \mathrm{z} 243$, corresponding to the formation of lumichrome (LC) and lumiflavin (LF), as shown in Figure 10H,I, respectively [36].

As shown in Figures 5 and 6, the inactivation rates of $69.1 \%$ and $90.1 \%$ for E. coli were achieved via 10 and $25^{\circ} \mathrm{C}$ for $50 \mu \mathrm{g} / \mathrm{mL}$ of TC treatments, respectively. It seems that for $E$. coli, the higher the temperature treatment of TC, the higher the reduction percentage. As shown in Figure 5, a 94.3\% viability of E. coli was retained in the TCF treatment with $20 \mathrm{~W} / \mathrm{m}^{2}$ blue light irradiation at $10{ }^{\circ} \mathrm{C}$ for $2 \mathrm{~h}$ $\left(14.4 \mathrm{~J} / \mathrm{cm}^{2}\right.$, high-energy dose). The antibiotic ability of TC for E. coli was noticed as increasing in a temperature-dependent manner in this study. However, for the TCF treatment with $20 \mathrm{~W} / \mathrm{m}^{2}$ of blue light irradiation at $25^{\circ} \mathrm{C}$ for $1 \mathrm{~h}\left(7.2 \mathrm{~J} / \mathrm{cm}^{2}\right.$, low-energy dose), a $93.2 \%$ viability of $E$. coli was shown in this study. At a low-energy dosage, the photosensitizer might use FMN treated at a high temperature to increase E. coli viability. This suggests that the photodegradation of TC in FMN solution may also reduce its antibiotic property in relation to microorganisms at room temperature.

It has been reported that, for the structurally-related activity of TC, each of the rings in the linearly fused tetracyclic nucleus must be six-membered for the molecules to maintain their antibacterial activity [1]. The major ion fragment of TC was found to be $\mathrm{m} / \mathrm{z} 445.1$. However, after the TCF treatments at $25^{\circ} \mathrm{C}$ for 0.5 and $1 \mathrm{~h}$, TC was found to be $99.4 \%$ and $100 \%$ decomposed, respectively, in this study. The major ion fragment of the mass spectrum of D-TCF was $\mathrm{m} / \mathrm{z} 431.0$, as observed via the TCF treatment in this study. However, after the TCF treatments at $25^{\circ} \mathrm{C}$ for 0.5 and $1 \mathrm{~h}$, the viabilities rates of $64.8 \%$ and $93.2 \%$ for $E$. coli were achieved via $50 \mu \mathrm{g} / \mathrm{mL}$ of D-TCF solution. It was suggested that TCF treatment reduces the antibiotic property of TC in an energy-dependent manner, and blue light irradiation and the D-TCF from the TCF treatment had less antibacterial activity in relation to E. coli.

TC and FMN are both sensitive to blue light irradiation, with $\mathrm{O}_{2} \bullet^{-}$being produced via the photolytic process. It has been reported that demeclocycline is a semisynthetic tetracycline that is photosensitive to violet light $(415 \mathrm{~nm})$. ROS generated from demeclocycline photolysis under violet light irradiation can inactivate methicillin-resistant S. aureus (MRSA) and E. coli bacteria [37]. FMN is also sensitive to violet light, with a higher efficiency in the inactivation of $S$. aureus via the decomposition of FMN by photolysis, as compared to blue light irradiation at the same radiant intensity [27]. It is therefore of interest in the study of the conformational changes of TC and its antibiotic behavior upon the FMN photolytic process under violet irradiation.

The wavelength of the maximum emission of blue light applied in this study was $462 \mathrm{~nm}$. It is well known that the white LED spectrum is a combination of different color lights. The efficiency of FMN photolysis by white LED light was found to be about 75\%, which is similar to that of FMN photolysis by blue LED light at the same intensity [15]. As an energy-efficient light source, white LED lamps can be applied to replace a blue LED light source for TC degradation during FMN photolysis treatment, though its efficiency is lower [10]. Blue light irradiation at $20 \mathrm{~W} / \mathrm{m}^{2}$ for $2 \mathrm{~h}$ had almost the same efficiency as solar radiation by sunshine for $30 \mathrm{~min}$ in terms of crystal violet degradation during riboflavin photolysis, occurring together with ROS generation [15]. ROS generated from the NBT reduction method were relatively lower in riboflavin than they were in FMN at an equivalent illumination level. When the sun is shining brightly, sunlight could be the primary source of radiation for TC degradation under the FMN photolytic process. 


\section{Conclusions}

This study established that FMN photolysis with blue light $(\lambda=462 \mathrm{~nm})$ irradiation degrades TC by ROS generation. For TC in the presence of FMN in a phosphate solution irradiated by blue light, the structural change of TC occurred via the pathways involving ROS. TC degradation caused by FMN photolysis protocols can highly decrease the antimicrobial ability of TC and conceivably reduce its influence on ecosystems containing environmental microflora. Therefore, FMN photolysis treatment under blue light irradiation is an easy and a secure means to decrease the antimicrobial ability of TC in solution and perhaps other types of antibiotic compounds.

Author Contributions: Data curation, S.-T.H. and J.-M.P.Y.; formal analysis, C.-Y.W. and S.H.; investigation, J.-Y.L.; methodology, C.-Y.W.; project administration, C.-W.C.; visualization, S.-T.H. and J.-M.P.Y.; writing-original draft, J.-Y.L.; writing-review and editing, S.-Y.L. and S.-H.W.

Funding: This research received no external funding.

Acknowledgments: The authors appreciate Yi-An Hung for her assistance in performing the experimental work.

Conflicts of Interest: The authors declare no conflict of interest.

\section{References}

1. Chopra, I.; Roberts, M. Tetracycline antibiotics: Mode of action, applications, molecular biology, and epidemiology of bacterial resistance. Microbiol. Mol. Biol. Rev. 2001, 65, 232-260. [CrossRef]

2. Roberts, M.C. Tetracycline resistance determinants: Mechanisms of action, regulation of expression, genetic mobility, and distribution. FEMS. Microbiol. Rev. 1996, 19, 1-24. [CrossRef]

3. Daghrir, R.; Drogui, P. Tetracycline antibiotics in the environment: A review. Environ. Chem. Lett. 2013, 11, 209-227. [CrossRef]

4. Chen, Y.; Hu, C.; Qu, J.; Yang, M. Photodegradation of tetracycline and formation of reactive oxygen species in aqueous tetracycline solution under simulated sunlight irradiation. J. Photochem. Photobiol. A Chem. 2008, 197, 81-87. [CrossRef]

5. $\quad$ Redelsperger, I.M.; Taldone, T.; Riedel, E.R.; Lepherd, M.L.; Lipman, N.S.; Wolf, F.R. Stability of doxycycline in feed and water and minimal effective doses in tetracycline-inducible systems. J. Am. Assoc. Lab. Anim. Sci. 2016, 55, 467-474.

6. Andreozzi, R.; Raffaele, M.; Nicklas, P. Pharmaceuticals in STP effluents and their solar photodegradation in aquatic environment. Chemosphere 2003, 50, 1319-1330. [CrossRef]

7. Huang, S.T.; Wu, C.Y.; Lee, N.Y.; Cheng, C.W.; Yang, M.J.; Hung, Y.A.; Wong, T.W.; Liang, J.Y. Effects of $462 \mathrm{~nm}$ light-emitting diode on the inactivation of Escherichia coli and a multidrug-resistant by tetracycline photoreaction. J. Clin. Med. 2018, 7, 278. [CrossRef]

8. Yuann, J.M.P.; Wang, J.S.; Jian, H.L.; Lin, C.C.; Liang, J.Y. Effects of Clinacanthus nutans (Burm. f) Lindau leaf extracts on protection of plasmid DNA from riboflavin photoreaction. MC-Trans. Biotech. 2012, 4, 45-59.

9. Jian, H.L.; Cheng, C.W.; Chen, L.Y.; Liang, J.Y. The photochemistry of riboflavin. MC-Trans. Biotechnol. 2011, 3, 1-11.

10. Lin, Y.; Eitenmiller, R.R.; Landen, W.O. Riboflavin. In Vitamin Analysis for the Health and Food Sciences, 2nd ed.; CRC Press: Boca Raton, Florida, USA, 2008; pp. 325-354.

11. Lu, C.Y.; Wang, W.F.; Lin, W.Z.; Han, Z.H.; Yao, S.D.; Lin, N.Y. Generation and photosensitization properties of the oxidized radical of riboflavin: A laser flash photolysis study. J. Photochem. Photobiol. B Biol. 1999, 52, 111-116. [CrossRef]

12. Sato, K.; Taguchi, H.; Maeda, T.; Minami, H.; Asada, Y.; Watanabe, Y.; Yoshikawa, K. The primary cytotoxicity in ultraviolet-a-irradiated riboflavin solution is derived from hydrogen peroxide. J. Investig. Dermatol. 1995, 105, 608-612. [CrossRef]

13. Tripathi, A.K.; Dwivedi, A.; Pal, M.K.; Rastogi, N.; Gupta, P.; Ali, S.; Prabhu, M.B.; Kushwaha, H.N.; Ray, R.S.; Singh, S.K.; et al. Attenuated neuroprotective effect of riboflavin under UV-B irradiation via miR-203/c-Jun signaling pathway in vivo and in vitro. J. Biomed. Sci. 2014, 21, 39. [CrossRef]

14. Liang, J.Y.; Yuann, J.M.; Cheng, C.W.; Jian, H.L.; Lin, C.C.; Chen, L.Y. Blue light induced free radicals from riboflavin on E. coli DNA damage. J. Photochem. Photobiol. B Biol. 2013, 119, 60-64. [CrossRef] 
15. Liang, J.Y.; Cheng, C.W.; Yu, C.H.; Chen, L.Y. Investigations of blue light-induced reactive oxygen species from flavin mononucleotide on inactivation of E. coli. J. Photochem. Photobiol. B Biol. 2015, 143, 82-88. [CrossRef]

16. Ottaway, P.B. Stability of vitamins in food. In The Technology of Vitamins in Food; Chapman and Hall: London, UK, 1993; pp. 233-244.

17. Yang, M.Y.; Chang, C.J.; Chen, L.Y. Blue light induced reactive oxygen species from flavin mononucleotide and flavin adenine dinucleotide on lethality of HeLa cells. J. Photochem. Photobiol. B Biol. 2017, 173, 325-332. [CrossRef]

18. Liang, J.Y.; Yuann, J.P.; Hsie, Z.J.; Huang, S.T.; Chen, C.C. Blue light induced free radicals from riboflavin in degradation of crystal violet by microbial viability evaluation. J. Photochem. Photobiol. B: Biol. 2017, 174, 355-363. [CrossRef]

19. Bouafı-Cherguı, S.; Zemmourı, H.; Chabanı, M.; Bensma1lı, A. TiO2-photocatalyzed degradation of tetracycline: Kinetic study, adsorption isotherms, mineralization and toxicity reduction. Desalin. Water Treat. 2016, 57, 16670-16677. [CrossRef]

20. Reyes, C.; Fernandez, J.; Freer, J.; Mondaca, M.; Zaror, C.; Malato, S.; Mansilla, H. Degradation and inactivation of tetracycline by $\mathrm{TiO}_{2}$ photocatalysis. J. Photochem. Photobiol. A Chem. 2006, 184, 141-146. [CrossRef]

21. Cai, F.; Tang, Y.; Chen, F.; Yan, Y.; Shi, W. Enhanced visible-light-driven photocatalytic degradation of tetracycline by $\mathrm{Cr}_{3}{ }^{+}$doping $\mathrm{SrTiO}_{3}$ cubic nanoparticles. RSC Adv. 2015, 5, 21290-21296. [CrossRef]

22. Wang, H.; Yao, H.; Pei, J.; Liu, F.; Li, D. Photodegradation of tetracycline antibiotics in aqueous solution by UV/ZnO. Desalin. Water Treat. 2016, 57, 19981-19987. [CrossRef]

23. Saghi, M.; Mahanpoor, K. Photocatalytic degradation of tetracycline aqueous solutions by nanospherical $\alpha-\mathrm{Fe}_{2} \mathrm{O}_{3}$ supported on 12-tungstosilicic acid as catalyst: Using full factorial experimental design. Int. J. Ind. Chem. 2017, 8, 297-313. [CrossRef]

24. Yamal-Turbay, E.; Jaén, E.; Graells, M.; Pérez-Moya, M. Enhanced photo-Fenton process for tetracycline degradation using efficient hydrogen peroxide dosage. J. Photochem. Photobiol. A Chem. 2013, 267, 11-16. [CrossRef]

25. Castillo, C.; Criado, S.; Díaz, M.; García, N.A. Riboflavin as a sensitiser in the photodegradation of tetracyclines. Kinetics, mechanism and microbiological implications. Dyes Pigm. 2007, 72, 178-184. [CrossRef]

26. Jiao, S.; Zheng, S.; Yin, D.; Wang, L.; Chen, L. Aqueous photolysis of tetracycline and toxicity of photolytic products to luminescent bacteria. Chemosphere 2008, 73, 377-382. [CrossRef]

27. Wong, T.W.; Cheng, C.W.; Hsieh, Z.J.; Liang, J.Y. Effects of blue or violet light on the inactivation of Staphylococcus aureus by riboflavin-5'-phosphate photolysis. J. Photochem. Photobiol. B Biol. 2017, 173, 672-680. [CrossRef]

28. Yang, M.J.; Hung, Y.A.; Wong, T.W.; Lee, N.Y.; Yuann, J.M.; Huang, S.T.; Wu, C.Y.; Chen, I.Z.; Liang, J.Y. Effects of blue-light-induced free radical formation from catechin hydrate on the inactivation of Acinetobacter baumannii, Including a carbapenem-resistant strain. Molecules 2018, 23, 1631. [CrossRef]

29. Cheng, C.W.; Chen, L.Y.; Chou, C.W.; Liang, J.Y. Investigations of riboflavin photolysis via coloured light in the nitro blue tetrazolium assay for superoxide dismutase activity. J. Photochem. Photobiol. B Biol. 2015, 148, 262-267. [CrossRef]

30. Russell, L.V.; Vanderslice, J.T. Comprehensive review of vitamin $\mathrm{B}_{2}$ analytical methodology. J. Micronutr. Anal. 1990, 8, 257-310.

31. Barua, M.G.; Escalada, J.P.; Bregliani, M.; Pajares, A.; Criado, S. Antioxidant capacity of (+)-catechin visible-light photoirradiated in the presence of vitamin $B_{2}$. Redox Rep. 2017, 22, 282-289. [CrossRef]

32. Huvaere, K.; Sinnaeve, B.; Van Bocxlaer, J.; Skibsted, L.H. Flavonoid deactivation of excited state flavins: Reaction monitoring by mass spectrometry. J. Agric. Food Chem. 2012, 60, 9261-9272. [CrossRef]

33. Massad, W.A.; Bertolotti, S.; Garcia, N.A. Kinetics and mechanism of the vitamin $\mathrm{B}_{2}$-sensitized photooxidation of isoproterenol. Photochem. Photobiol. 2004, 79, 428-433. [CrossRef] [PubMed]

34. Xie, L.J.; Wang, R.L.; Wang, D.; Liu, L.; Cheng, L. Visible-light-mediated oxidative demethylation of $\mathrm{N}$ 6-methyl adenines. J. Chem. Soc. Chem. Commun. 2017, 53, 10734-10737. [CrossRef] [PubMed]

35. Ji, Y.; Shi, Y.; Dong, W.; Wen, X.; Jiang, M.; Lu, J. Thermo-activated persulfate oxidation system for tetracycline antibiotics degradation in aqueous solution. Chem. Eng. J. 2016, 298, 225-233. [CrossRef] 
36. Huvaere, K.; Cardoso, D.R.; Homem-de-Mello, P.; Westermann, S.; Skibsted, L.H. Light-induced oxidation of unsaturated lipids as sensitized by flavins. J. Phys. Chem. B 2010, 114, 5583-5593. [CrossRef] [PubMed]

37. He, Y.; Huang, Y.Y.; Xi, L.; Gelfand, J.A.; Hamblin, M.R. Tetracyclines function as dual-action light-activated antibiotics. PLoS ONE 2018, 13, e0196485. [CrossRef]

(C) 2019 by the authors. Licensee MDPI, Basel, Switzerland. This article is an open access article distributed under the terms and conditions of the Creative Commons Attribution (CC BY) license (http://creativecommons.org/licenses/by/4.0/). 